\title{
High strain rate characterization of ZEK100 magnesium rolled alloy sheet
}

\author{
S. Kurukuri ${ }^{1}$, A. Bardelcik ${ }^{1}$, M.J. Worswick ${ }^{1}$, R.K. Mishra ${ }^{2}$, and J.T. Carter ${ }^{2}$ \\ ${ }^{1}$ University of Waterloo, Waterloo, ON, N2L 3G1, Canada \\ ${ }^{2}$ General Motors Research \& Development, Warren, MI 48090, USA
}

\begin{abstract}
In this paper, the constitutive behaviour of a rare-earth magnesium alloy ZEK100 sheet is studied at room temperature and over a wide range of strain rates. The tensile data from $1.6 \mathrm{~mm}$ thick ZEK100 sheets at quasi-static and high strain rate conditions show strong in-plane anisotropy of tensile properties, such as yield and ultimate strengths, failure strain and work hardening rates. The results also show a decrease in strength and increase in ductility as the orientation changes from the rolling to the transverse direction. The work hardening behaviour is shown to be much stronger in the transverse direction when compared to the rolling and $45^{\circ}$ directions. The change in stress with respect to strain rate also varied strongly with orientation. The cause of the in-plane anisotropy and strain rate dependence of tensile properties is attributed to the as-rolled crystallographic textures and the active deformation mechanisms.
\end{abstract}

\section{Introduction}

Wrought magnesium alloys are attractive for use in the automotive industry due to their low density and high specific strength, which leads to potential improvements in fuel efficiency and reduced emissions due to weight reduction. However, commercial magnesium alloys, such as AZ31B sheet usually have poor formability and limited ductility at room temperature due to a pronounced basal texture [1], which limits their industrial application. One of the techniques used to improve the room temperature formability of magnesium alloys is the addition of rare earth elements such as $\mathrm{Ce}, \mathrm{Nd}, \mathrm{Y}$ and $\mathrm{Gd}$, for example, which have been shown to weaken the basal texture [1].

Prior to the introduction of rare-earth magnesium alloys in automotive body structures, their forming and crash performance must be known. Deformation under a wide range of strain rates occurs during a car crash, with high strain rate deformation being operative in some regions. Moreover, in some innovative metalworking processes, such as electromagnetic forming or explosive forming, materials undergo large amounts of strain at high strain rate [2]. This paper focuses on the tensile characterization of a rare-earth magnesium alloy, ZEK100 sheet, over a wide range of strain rates. In order to detect any inplane anisotropy of the mechanical properties, tests were performed in the rolling and transverse directions and at $45^{\circ}$ with respect to the rolling directions (respectively RD, TD and $45^{\circ}$ ).

\section{Experimental procedure}

A rolled rare-earth magnesium alloy sheet, ZEK100 (1.3\%wt. Zn, 0.2\%wt. Nd, $0.25 \%$ wt. $\mathrm{Zr}$ and $0.01 \%$ wt. $\mathrm{Mn}$ ) was used in this study in an as-received (F-temper) condition. The nominal thickness of the sheet is $1.6 \mathrm{~mm}$ and the pole figure of initial texture is shown in figure 1.

Tests at low strain rate $\left(0.001 \mathrm{~s}^{-1}, 0.01 \mathrm{~s}^{-1}\right.$ and $\left.0.1 \mathrm{~s}^{-1}\right)$ were performed using an Instron tensile testing apparatus.
High strain rate $\left(500 \mathrm{~s}^{-1}\right.$ and $\left.1,000 \mathrm{~s}^{-1}\right)$ tests were performed using a tensile split Hopkinson bar (TSHB). The miniature dog-bone specimen geometry shown in figure 2 was used for all of the testing conducted in this work. This geometry has a gauge length of $12.5 \mathrm{~mm}$, which was small enough to ensure dynamic equilibrium during the highrate experiments. This specimen geometry has been shown to produce stress-strain results similar to ASTM tensile specimens up to the ultimate tensile strength (UTS) for a range of materials, such as magnesium [3], aluminum [4] and advanced high strength steels [5].

\subsection{Quasi-static tests}

The quasi-static experiments were performed using a servohydraulic Instron (Model 1331) tensile testing machine. The specimen was mounted in a pair of grips, as shown in figure 3 , and the elongation was measured using a $12.5 \mathrm{~mm}$ gauge length $( \pm 5 \mathrm{~mm}$ span) extensometer. The constant cross-head velocity was set to $0.0125 \mathrm{~mm} / \mathrm{s}, 0.125 \mathrm{~mm} / \mathrm{s}$ and $1.25 \mathrm{~mm} / \mathrm{s}$ to deform the specimen at nominal initial strain rates of $0.001 \mathrm{~s}^{-1}, 0.01 \mathrm{~s}^{-1}$ and $0.1 \mathrm{~s}^{-1}$, respectively. Three repeat tests were conducted for each strain rate.

\subsection{Tensile split Hopkinson bar apparatus}

The high strain rate tensile experiments were conducted using a tensile split Hopkinson bar (TSHB) apparatus. A schematic diagram of the tensile split Hopkinson bar at the University of Waterloo is presented in figure 4.

The apparatus comprises a hollow striker and incident and transmitter bars made of high tensile nickel chrome steel (AISI 4340). The striker bar is propelled towards the incident bar end cap with a gas gun. Upon impacting the end cap, the striker bar creates an elastic tensile impulse in the incident bar, which propagates towards the specimen, causing it to deform plastically. During deformation, a portion of the stress wave is transmitted through the 


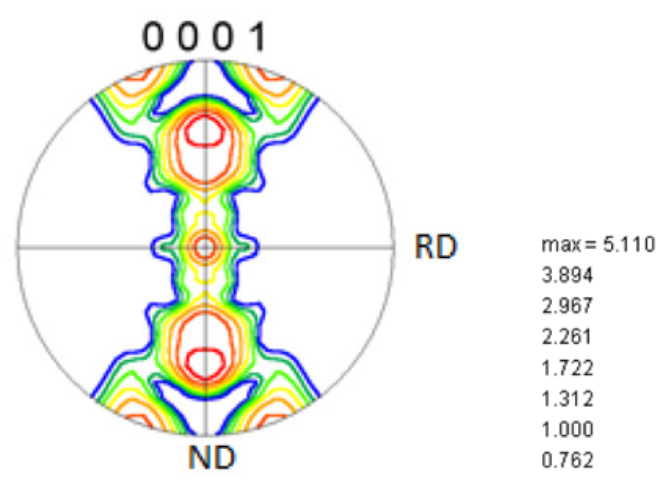

Fig. 1. Pole figure of initial texture of ZEK100 sheet.

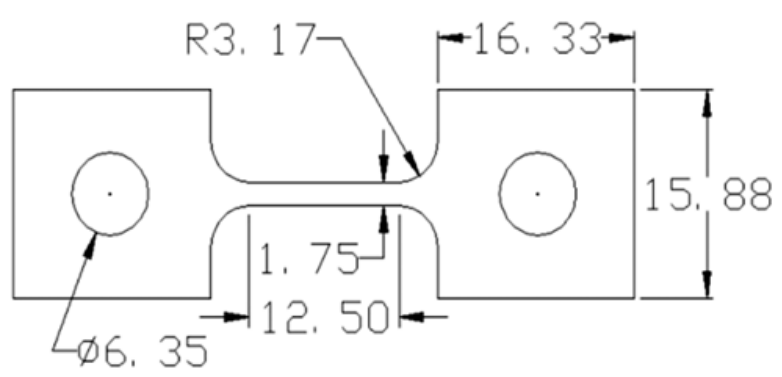

Fig. 2. Miniature dog-bone specimen (dimensions are in $\mathrm{mm}$ ).

specimen to the transmitter bar while the remainder of the pulse is reflected. The incident, reflected and transmitted pulses are measured using strain gauges mounted on the incident and transmitter bars. These waves are then used to determine the behaviour of the specimen using the analysis presented by Salisbury et al. [6]. At least three repeat tests were conducted for each strain rate.

\section{Results and discussion}

The average true stress versus plastic strain curves in the $\mathrm{RD}$, TD and $45^{\circ}$ direction for the low and high strain rate experiments are shown in figure 5 and figure 6 , respectively. These data demonstrate that the ZEK100 sheet exhibits strong in-plane anisotropy with the yield strength being the lowest in the TD and highest in the RD at all strain rates.

Figure 7 depicts the work hardening rate $v s$. plastic strain for the ZEK100 samples tested at a strain rate of $0.1 \mathrm{~s}^{-1}$. Note that, similar trends were observed at all strain rates. The data reveals a significant change in work hardening rate with loading orientation. For example, at a plastic strain of 0.04 , the work hardening rate in the RD is approximately $500 \mathrm{MPa}$ whereas the $45^{\circ}$ and TD orientations exhibit rates of 1150 and $1550 \mathrm{MPa}$, respectively.

Figure 8 is a plot of ultimate tensile strength (UTS) and yield strength (YS) versus orientation and shows a reduction in strength as the orientation changes from $0^{\circ}$ to $90^{\circ}$. The yield strength level drops nearly $100 \mathrm{MPa}$ but the UTS changes relatively little as the orientation changes from $0^{\circ}$ to $90^{\circ}$.

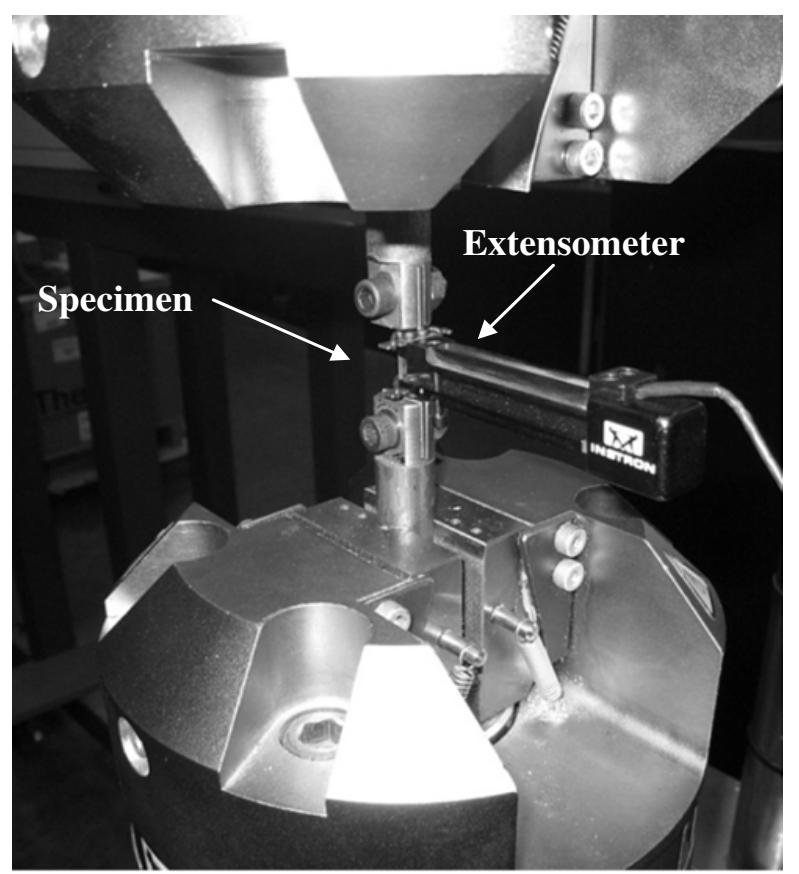

Fig. 3. Quasi-static experimental setup.

Figure 9 illustrates that the uniform elongation and failure strains also change as the orientation changes from the RD to TD. Specifically, the uniform strain more than doubles and the elongation at fracture increases by $50 \%$ when the pulling direction is changed from the RD to TD.

The effect of orientation is further examined by fitting the true stress-strain curves with a power law function. The strength coefficient, $C$ and the strain-hardening exponent, $n$, are plotted in figure 10 . These fits reveal that orientation has a strong effect on the hardening parameters of the ZEK100 alloy sheet, since the values of $C$ and $n$ are much higher for the $45^{\circ}$ and transverse directions compared to the rolling direction.

The large variation in tensile properties, especially the yield strength and the work hardening rates, are likely due to the initial crystallographic texture and, therefore, the active deformation mechanisms [7,8]. For instance, the texture data shown in figure 1 show that the c-axes of some grains are tilted in the transverse direction compared to commercial sheet alloys such as AZ31B. (The c-axes in typical rolled AZ31B sheet are mostly parallel to the normal direction, with some tilted a few degrees towards RD). This texture in the ZEK100 sheet results in basal slip and possibly extension twinning along with non-basal slip in the remaining grains, leading to a drop in initial yield strength and increased work hardening rates in the samples pulled along the TD and $45^{\circ}$ directions. The stress-strain response in the RD is consistent with a lack of slip systems for easy slip [7-10].

The dependency of the stress-strain behaviour of ZEK100 sheet on strain rate is illustrated in figure 11, 12 and 13 for the RD, TD and $45^{\circ}$ orientations, respectively. In the RD, there is a clear increase of the yield strength as the strain rate increases, as shown in figure 11. Over the entire range of strain rates considered, the yield strength level increased by approximately $75 \mathrm{MPa}$ for the RD, 


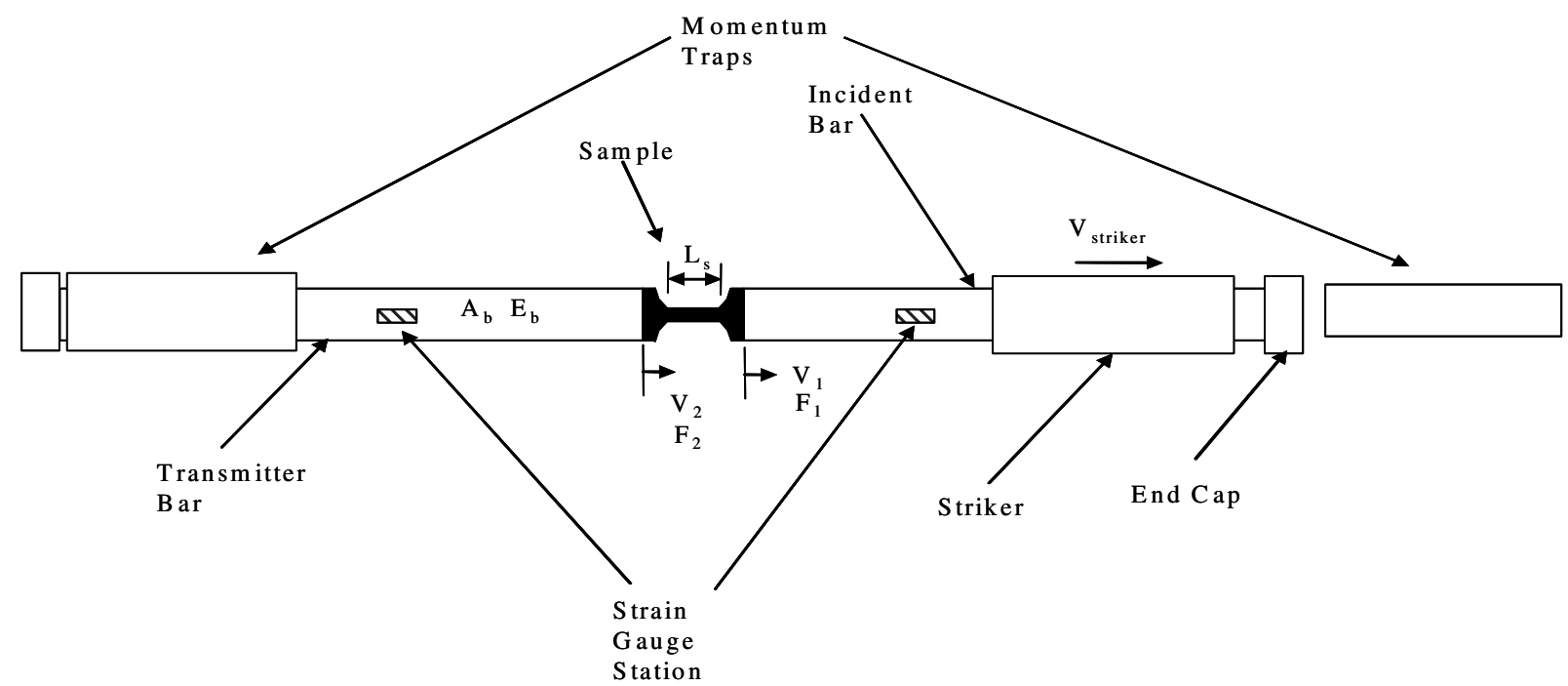

Fig. 4. Schematic diagram of TSHB apparatus at University of Waterloo.

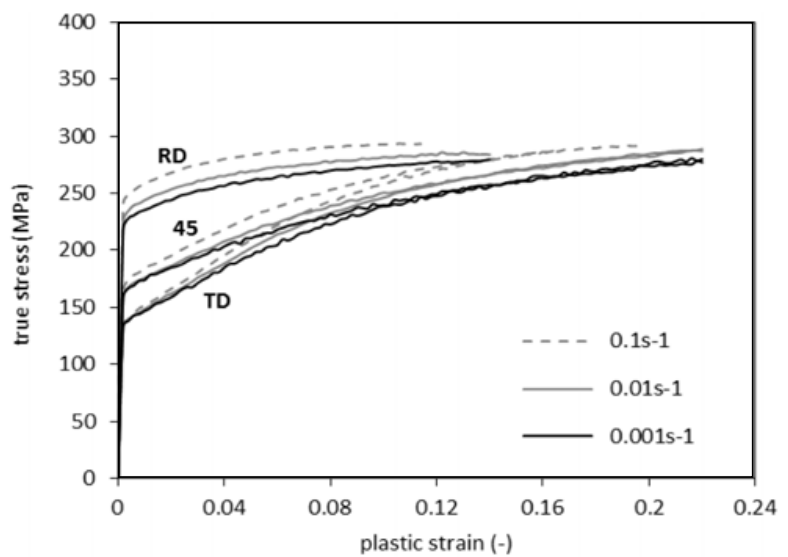

Fig. 5. True stress $v s$. plastic strain curves of quasi-static tests at $0.001 \mathrm{~s}^{-1}, 0.01 \mathrm{~s}^{-1}$ and $0.1 \mathrm{~s}^{-1}$ in the RD, TD and $45^{\circ}$ direction.

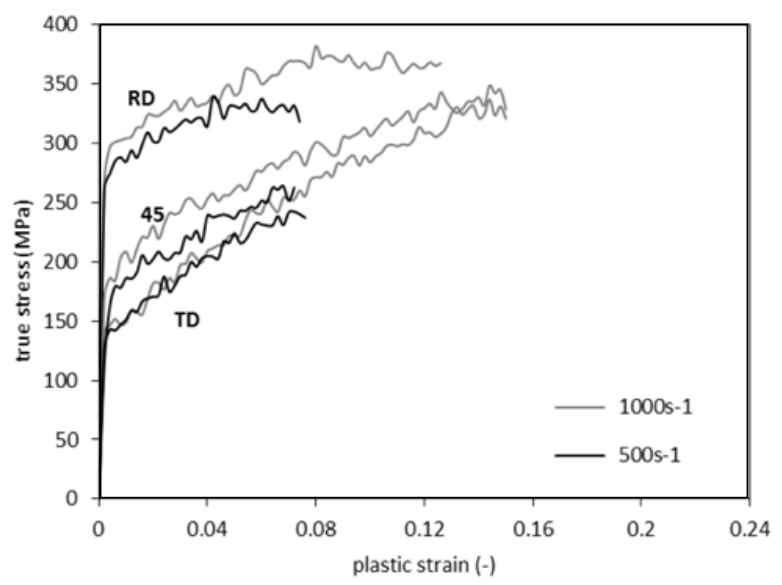

Fig. 6. True stress $v s$. plastic strain curves of high strain rate tests at $500 \mathrm{~s}^{-1}$ and $1000 \mathrm{~s}^{-1}$ in the RD, TD and $45^{\circ}$ direction.

which represents an average increase of $25 \%$. It is reported in the literature that for tension tests in the RD, non-basal (mainly prismatic) systems were generally activated, since basal planes are unfavourably oriented for slip in most of the grains. Basal slip, however, is also activated to some

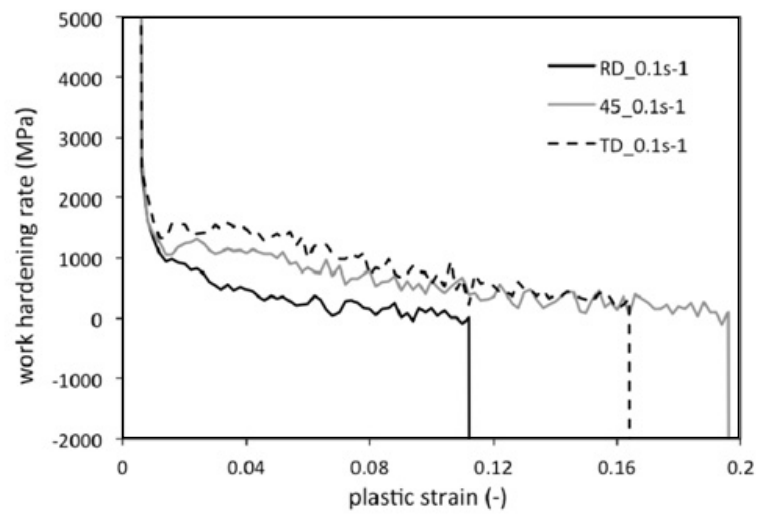

Fig. 7. Effect of orientation on work hardening rate for ZEK100 sheet at a strain rate of $0.1 \mathrm{~s}^{-1}$.

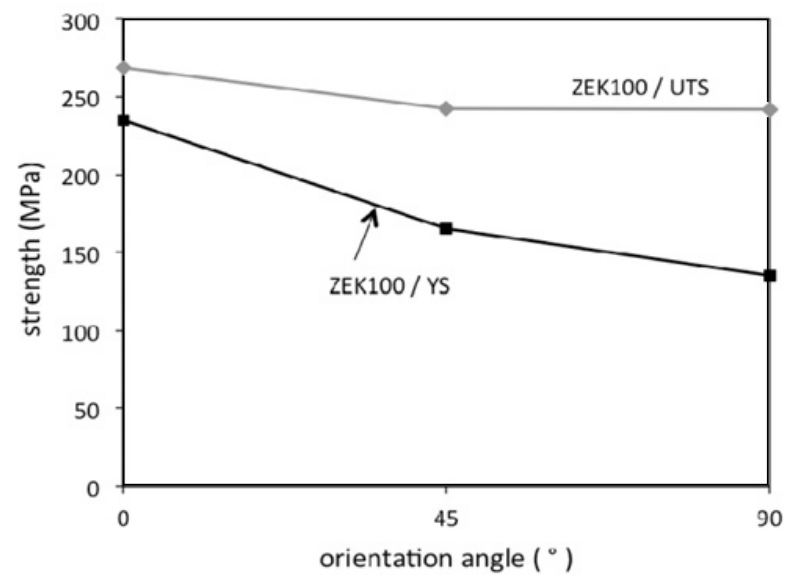

Fig. 8. Effect of orientation on UTS and YS for ZEK100 sheet at a strain rate of $0.1 \mathrm{~s}^{-1}$.

extent when the crystallographic c-axes are favourably oriented in the loading direction [7-10]. The increase of tensile yield stress with the increase of strain rate can mainly be attributed to the strain rate dependency of the CRSS of non-basal slip systems. This behavior is 


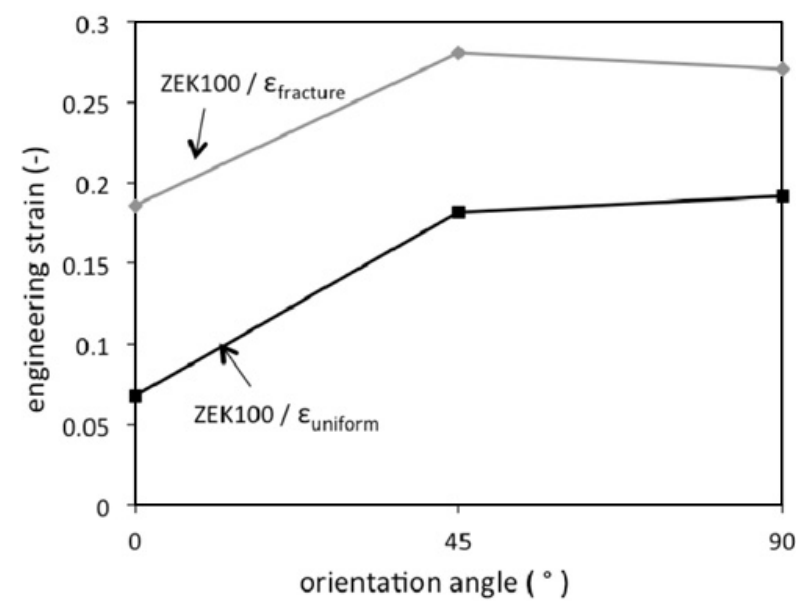

Fig. 9. Effect of orientation on uniform elongation and fracture strains for ZEK100 sheet at a strain rate of $0.1 \mathrm{~s}^{-1}$.

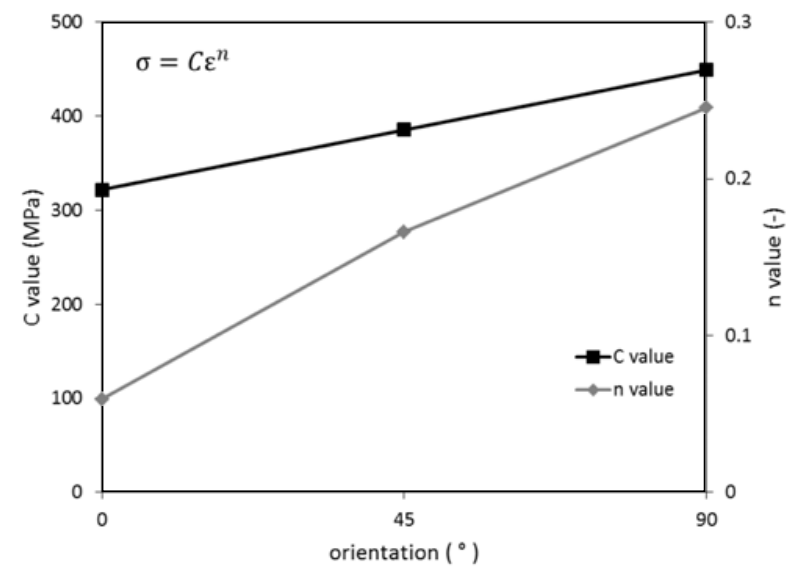

Fig. 10. Effect of orientation on power law hardening parameters for ZEK100 sheet at a strain rate of $0.1 \mathrm{~s}^{-1}$.

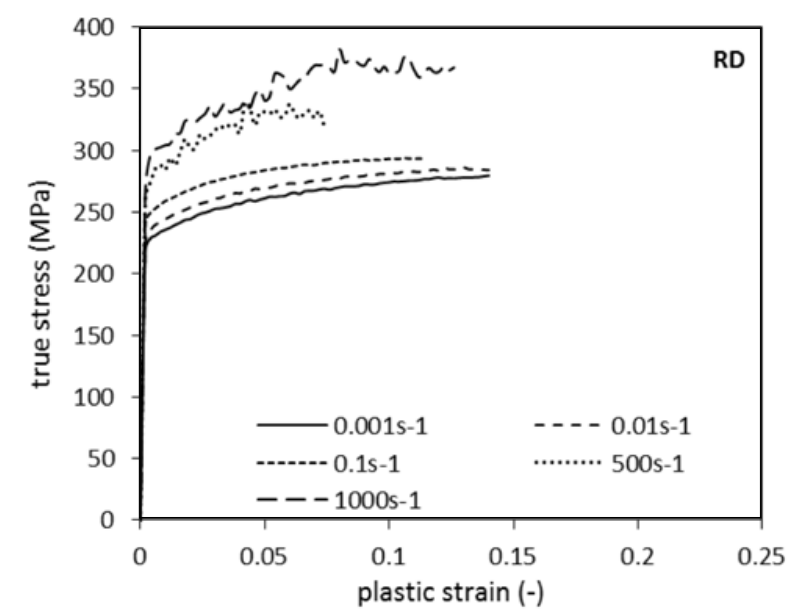

Fig. 11. Effect of strain rate on the flow curves of ZEK100 sheet in the RD.

commonly observed in typical commercial rolled AZ31B sheet $[7,9]$.

It is observed in figure 12 that when the tensile loading is applied in the transverse direction, the yield stress is strain rate insensitive, but the work hardening rate increases for higher rates of loading. This is related to the

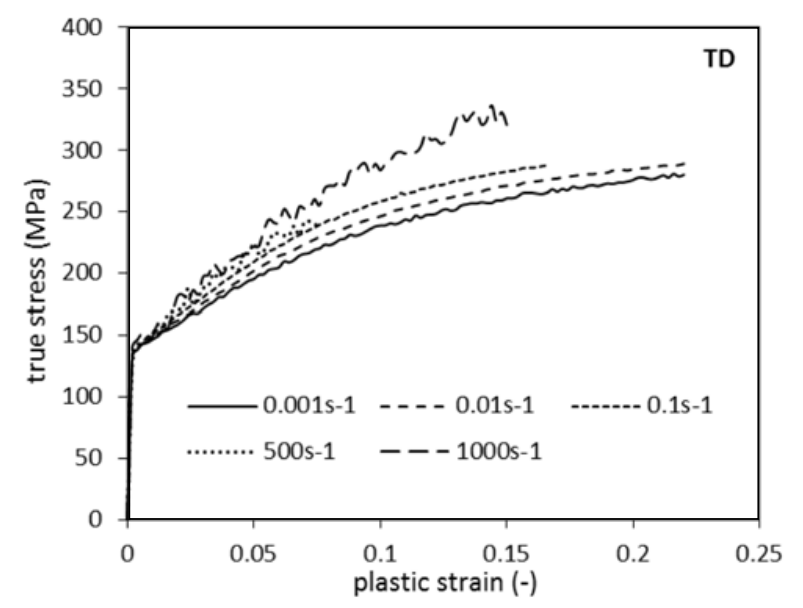

Fig. 12. Effect of strain rate on the flow curves of ZEK100 sheet in the TD.

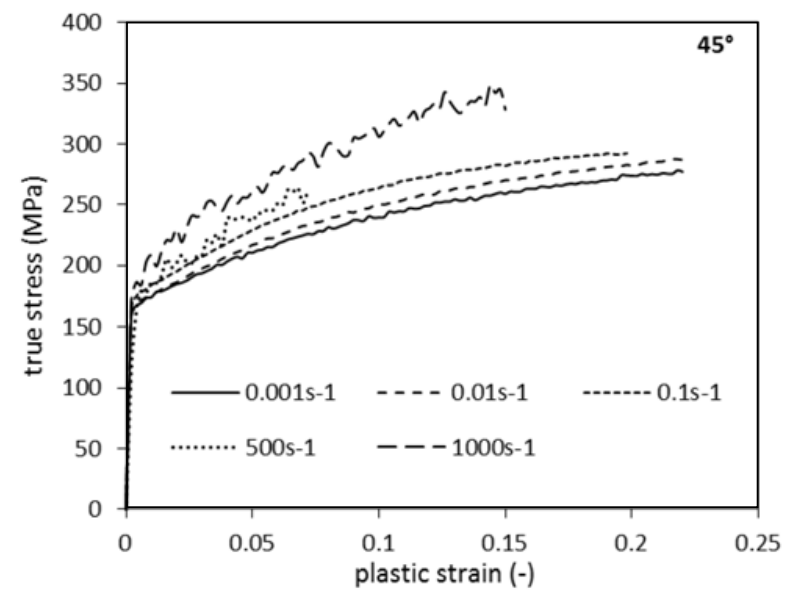

Fig. 13. Effect of strain rate on the flow curves of ZEK100 sheet in the $45^{\circ}$ orientation.

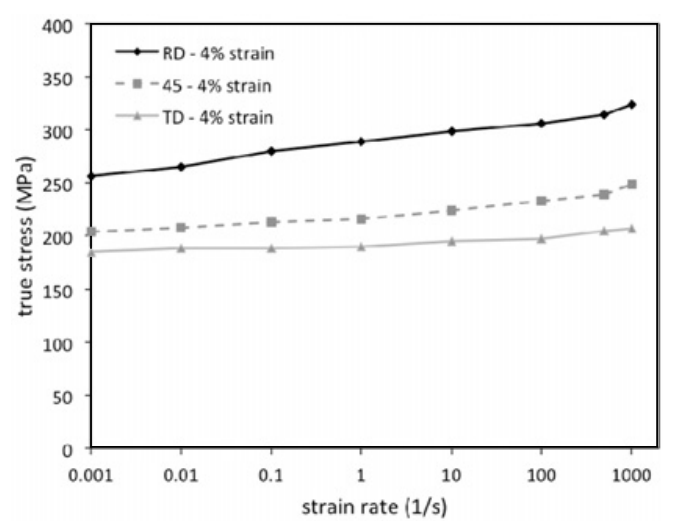

Fig. 14. True stress $v s$. strain rate for ZEK100 sheet in the RD, $\mathrm{TD}$ and $45^{\circ}$ orientation at $4 \%$ strain.

strain rate independency of the CRSS of basal slip systems and the extension twinning mechanisms activated in the majority of the grains for which the crystallographic c-axes are favorably oriented towards the transverse direction in the initial material [9].

Figure 13 illustrates the true stress-plastic strain curves corresponding to the tensile tests carried out on the $45^{\circ}$ orientation samples and exhibits a moderate strain rate dependency of yield strength and work hardening rates 


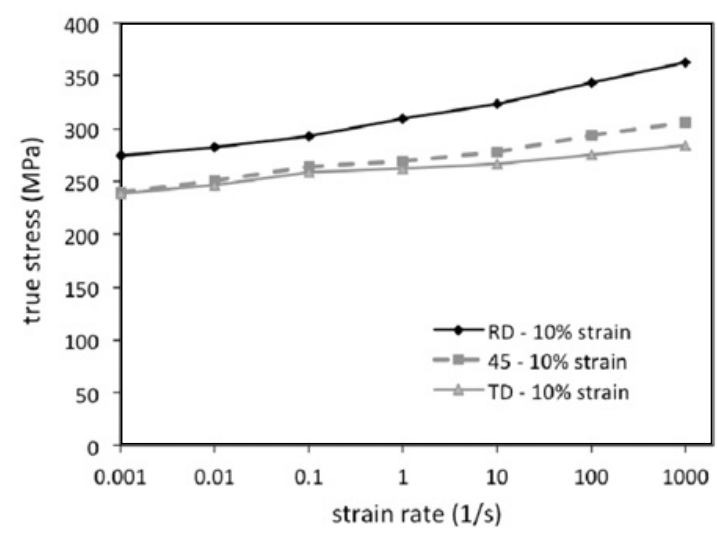

Fig. 15. True stress vs. strain rate for ZEK100 sheet in the RD, TD and $45^{\circ}$ orientation at $10 \%$ strain.

when compared to the TD samples. This could be due to a lower fraction of grains with c-axes favourably tilted in the deformation direction than occurs for TD loading orientations.

It is interesting to note that the RD response of the current ZEK100 alloy displays a response similar to that exhibited by bcc metals for which yield strength is strongly rate sensitive, but hardening rate is often rate insensitive [11]. This type of behavior can also be observed in commercial AZ31B rolled sheets, irrespective of sheet orientation [7,9]. In contrast, the TD and $45^{\circ}$ orientations exhibit the opposite behaviour; that is, the yield strength appears rate insensitive, while the hardening rate is strongly rate sensitive. These results demonstrate the importance of accounting for crystallographic texture in future constitutive model development efforts.

Figures 14 and 15 plot the true stress at $4 \%$ and $10 \%$ strain, respectively, as a function of strain rate (logarithmic scale) for the $\mathrm{RD}, \mathrm{TD}$ and $45^{\circ}$ orientations. The flow stress in the transverse and $45^{\circ}$ directions exhibits almost no strain rate sensitivity at low strains (4\% strain); however, the rate sensitivity increases with increased strain (see Figure 15 for a strain of $10 \%$, for example). On the other hand, tests in the rolling direction exhibit pronounced rate sensitivity over the entire strain range (compare Figures 14 and 15).

\section{Summary}

The ZEK100 sheet exhibits strong in-plane anisotropy, with significantly lower yield strength, higher hardening rates and increased ductility as the orientation changes from the RD to TD. The low to high strain rate tensile experiments also reveal a significant orientation dependence of the strain rate sensitivity. In the $\mathrm{RD}$, the rate sensitivity has a significant effect on the yield strength, but a relatively mild effect on hardening rate. This response is attributed to the strain rate dependency of the CRSS of the activated non-basal slip systems. In the $\mathrm{TD}$, the rate sensitivity has little effect on the early yield response, however, the hardening rate increases significantly with strain rate. This behaviour is related to the strain rate independency of the CRSS of the basal slip and extension twinning mechanisms activated in grains for which the crystallographic c-axes are favorably oriented towards the transverse direction.

\section{Acknowledgements}

This research was carried out under the framework of the Research Program of the Magnesium Network (MagNET), Canada. Financial support from General Motors of Canada, MagNET and the Ontario Research Fund is gratefully acknowledged.

\section{References}

1. B. Mordikeand, T. Ebert, Mater. Sci. Eng. A, 302 (2001)

2. I. Ulacia, I. Hurtado, J. Imbert, C. Salisbury, M.J. Worswick, A. Arroyo, Steel Res. Int., 80 (2009)

3. D. Hasenpouth, MASc Thesis, University of Waterloo, (2010)

4. R. Smerd, S. Winkler, C. Salisbury, M. Worswick, D. Lloyd, M. Finn, Int. J. Imp. Eng. 32 (2005)

5. A.C. Thompson, C.P. Salisbury, M.J. Worswick, R. Mayer, J. de Phys. IV, 134 (2006)

6. C.P. Salisbury, MASc thesis, University of Waterloo (2001)

7. J. Min, J.T. Carter, R. Verma, Magnesium Technology 2012, TMS, Warrendale, PA (2012)

8. J. Min, Y. Cao, J.T. Carter, R. Verma, Magnesium Technology 2012, TMS, Warrendale, PA (2012)

9. I. Ulacia, N.V Dudamell, F. Gálvez, S. Yi, M.T. PérezPrado, I. Hurtado, Acta Mat. 58 (2010)

10. S.R. Agnew, Ö. Duygulu, Int. J. Plast. 21 (2005)

11. R.W. Armstrong, S.M. Walley, Int Mater Rev 53 (2008) 